\title{
Beatriz Sarlo, las lenguas del presente*
}

Beatriz Sarlo, the Languages of the Present

Sandra Contreras ${ }^{\text {a }}$

DOI: https://doi.org/10.11144/Javeriana.cl24.bslp

Universidad Nacional de Rosario, Argentina

sandracontreras123@gmail.com

Recibido: 12 Mayo 2017

Aceptado: 03 Julio 2017

Publicado: 28 Diciembre 2020

\section{Resumen:}

A partir de la premisa de que Beatriz Sarlo hace del vínculo con el presente el centro de una radical experiencia crítica, en este artículo mapeamos e interpretamos la serie de textos y de intervenciones en los que se redistribuye la intensidad de esa afección, en torno del año 2007, como punto de inflexión. La hipótesis es que es en esa redistribución de escritos y de prácticas de escritura (sintetizada en la edición del volumen Escritos de literatura argentina y en las columnas periodísticas del diario Perfil, luego reunidas en Ficciones argentinas), y no necesariamente en la que puede considerarse como su primera formulación programática de 1987 (la literatura escrita en el presente como crítica del presente), que es preciso leer en la obra de Beatriz Sarlo una teoría (crítica) del presente. Se trata de un cruce de experiencias con el tiempo (experiencias de choque, de fines, de recomienzos) que muestra, además y sobre todo, que lo que se ha modificado para Sarlo al cabo de esos veinte años (1987-2007), junto con el lugar y el valor del presente en la literatura (materia de una elaboración formaly de contenido que hay que representar), es el lugar y la función misma de la crítica en relación con el presente de esa literatura.

Palabras clave: Beatriz Sarlo, narrativa argentina contemporánea, presente-contemporáneo-actual.

\section{Abstract:}

Based on the premise that, for Beatriz Sarlo, a link with the present is the center of a radical critical experience, in this paper we locate, map and interpret the series of texts and interventions in which the intensity of this condition is redistributed, around the year 2007, as a turning point. Our hypothesis is that it is in this redistribution of writings and writing practices (synthesized in the volume Escritos de literatura argentina and in the journalistic articles published in the newspaper Perfil, and later gathered in Ficciones argentinas), and not necessarily in what can be considered as its first programmatic formulation of 1987 (literature written in the present as a critique of the present), that we must read in Beatriz Sarlo's work a (critical) theory of the present. This crossover of experiences with time (experiences of clashes, of ends, of re-establishments) also and above all shows that what has changed for Sarlo after these twenty years (1987-2007), together with the place and value of the present in literature (the subject of a formal elaboration/content to be represented), is the place and the very function of criticism in relation to the present of this literature.

Keywords: Beatriz Sarlo, contemporary Argentine narrative, present-contemporary-actual.

\section{Presente, actual, contemporáneo}

A diferencia de lo actual, que "puede no ser más que un ruido", el presente, decía Barthes, “está vivo”. Él establecía esta distinción cuando comenzaba a describir la prueba de la Separación (del mundo) para quien quiere escribir, y con ella remitía al sentimiento brusco de inadecuación entre la "actualidad candente" del Escribir, y la "actualidad del mundo circundante", que vuelve irrisorios los "pequeños investimentos personales" de quien busca saber "cómo encerrarse con vistas a una Obra literaria”. El presente, que es el material con el que la pulsión novelesca barthesiana establece un lazo afectivo - siempre que ese material se identifique con un estado subjetivo ("mi presente") —, es también en La preparación de la novela el tiempo propio de ese Deseo de Escribir que, aun cuando admita el arcaísmo de su objeto (la literatura) en el mundo

Notas de autor

\footnotetext{
a Autora de correspondencia. Correo electrónico: sandracontreras123@gmail.com
} 
de hoy, "resiste todas las presiones de la Actualidad como Figura de la Buena Integración, y surge siempre vivaz: extraordinariamente vivo" (350-351). Es, de algún modo, el presente idiorrítmico del escritor, en el que se anudan el principio de inactualidad y la pulsión de anacronismo, aquel en el que Barthes imagina también, por esos años y desde arcaicas experiencias comunitarias, el problema de la contemporaneidad: "Cómo vivir juntos en el tiempo" (Cómovivir 48).

"Barthesiana de por vida", como le gusta declararse ("Barthesianos" 11), Beatriz Sarlo hace de su vínculo con el presente - del vínculo de quien quiere leer con el presente- el centro de una radical experiencia crítica que también se debate con los ruidos de la actualidad y las señales de lo contemporáneo. Solo que lo hace traduciendo eso que descubrió en Barthes, "una sensibilidad y sus reflejos", a una lengua que es la misma ("presente", "actual”, "contemporáneo") y, sin embargo, otra. Porque, mientras lo contemporáneo se reserva para identificar, prioritariamente, aunque por cierto muy de vez en cuando, los rasgos de un dominio estético amplio (el arte contemporáneo) que no necesariamente implica a la literatura que se quiere leer (bien podríamos decir que, más que como narrativa o poesía contemporáneas, el corpus crítico de Sarlo se define como la "literatura argentina del presente"), lo actual no remite tanto a las demandas del mundo que presionan sobre los afectos personales - y solitarios - del escritor, como a la superficialidad de lo "fashion" (de la "onda"), que es la del error estético, el oportunismo y la impostación. Y el presente, el tiempo con el que Sarlo establece el lazo afectivo, porque es precisamente en él, antes que en el pasado, que se inscribe su pasión por la historia, es, aunque los énfasis del yo aparezcan una y otra vez, menos un estado subjetivo que una instancia de significación social; más aún, es un conglomerado de resonancias y afectos identificados como colectivos. ${ }^{1}$

En este sentido, está claro, y ha sido suficientemente dicho, que la opción ética - política y estéticade Beatriz Sarlo es - ahora con Adorno, también con Raymond Williams - la del impulso crítico de la modernidad. Su criterio de valor, el contenido de verdad de la obra de arte, esto es, la capacidad de la experiencia artística para devenir, en tanto mudo testigo de la catástrofe, una praxis cognitiva de la realidad: iluminación de una verdad social y epifanía de las contradicciones. Su hipótesis capital, a la hora de ponerse a leer enpresente durante los años de la dictadura y la posdictadura, es la idea de que "una zona importante de la literatura argentina, escrita y publicada en el país o en el exilio p [odía] ser leída como crítica del presente, incluso en los casos en que su referente primero [fuer]a el pasado" ("Política” 349). ${ }^{2}$

Pero, si estas son las premisas de una crítica que, sin por esto reivindicar "los derechos discutibles de la subjetividad soberana”, asume, con Peter Bürger, la necesidad de explicitar los lazos que unen al historiador con su propio presente y admite a la vez que sus elecciones "tienen un punto de referencia en el peso y la circulación social de los textos" ("Política” 334-335), ¿ por qué entonces remitirnos aquí a un Barthes como el de La preparación de la novela que, cuando lee, no necesita otra prueba de verdad que la perfección con que, por ejemplo, las palabras antiguas de Pascal expresan "las cosas presentes que están en él”, y nada más que en él? ("Política" 351). Sería difícil, por cierto, pasar por alto la distancia que se abre entre los intereses de una crítica (e historiadora) que lee según "la significación colectiva de una ficción", y las predilecciones de un crítico (patético) que lee afectado por intratables "momentos de verdad". Más aún, todo indica, por el contrario, que, si hay algo que Sarlo aprendió de Barthes sobre el arte de la lectura como crítica del presente, esas lecciones provienen, de modo evidente, no solo del Barthes sartreano y marxista de la moral de la forma, sino del crítico y teórico de las vanguardias que entiende la forma como revolución y a la escritura como transgresión de la Doxa y una resistencia al fascismo del lenguaje (véase "Roland Barthes"). Con todo, entiendo que esa mínima pero decisiva reorientación semántica que, como efecto de una implicancia vital entre tiempo subjetivo y deseo de escribir, Barthes imprime durante los últimos seminarios en las ideas de presente, actual y contemporáneo, resuena de algún modo en ese punto, en absoluto espectacular (porque ningún "cambio de vida" está implicado), aunque suficientemente significativo (porque alcanza a los modos del ensayo y por lo tanto a la escritura), en el que algo se modifica en el vínculo constitutivo de la crítica de Sarlo con la literatura del presente, en el que se redistribuye la intensidad de esa afección. 


\section{Mapas}

Pienso en el año 2007 como ese punto de inflexión. En el mes de abril, Sarlo publica el volumen Escritos sobre literatura argentina, y el modo en que selecciona, pero sobre todo ordena los artículos reunidos en la última parte, "Leer en presente", muestra, en la misma operación editorial, que no se trató nada más que de un criterio temático (incluir los ensayos cuyo objeto fue, entre 1980 y 2006, la literatura escrita y publicada mientras se leía), sino de un modo de leer la historia de su propio vínculo con el presente, casi una declaración. En la misma operación, separa de ese corpus los ensayos dedicados a Juan José Saer —el escritor que, en el sentido barthesiano del término, fue y sigue siendo, sin duda, su más estricto contemporáneo- para ubicarlos en la sección "Clásicos del siglo XX". Al mismo tiempo, a partir de octubre y desde el suplemento cultural del diario Perfil, recomienza, aunque según parámetros y formatos nuevos — digamos, desde otro lugar-, una lectura periódica de la "literatura del presente" (ahora la escrita y publicada a partir de 2007), que en 2012 reunirá en el volumen Ficciones argentinas. 33 ensayos, publicado por la editorial Mardulce. Mi hipótesis es que es en esa redistribución de escritos y de prácticas de escritura, y no necesariamente en la que -como diremos enseguida - puede considerarse en 1987 su primera formulación programática, que es preciso leer en la obra de Beatriz Sarlo una teoría (crítica) del presente. Es en el cruce de temporalidades (experiencias de choque, de fines, de recomienzos), que, por cierto, se monta con la emergencia fuerte de intervenciones sobre el presente - como las de Josefina Ludmer y las literaturas posautónomas, y, a la vez, con la interrupción de algunos de los mundos que la constituyeron (el cierre en 2008 de la revista Punto de Vista, que fundó y dirigió durante 30 años, pero también, en 2005, la muerte de Saer, seguida de la publicación póstuma de La grande) -, que cuaja en la escritura misma de Sarlo el presente como un afecto.

En efecto, el hecho de abrir la sección "Leer en presente" con el ya clásico "Política, ideología y figuración literaria" y no con los artículos que, aunque publicados entre 1984 y 1986, se incluyen a continuación (los artículos sobre Fuego a discreción de Antonio Dal Masetto, Elpasajero de Rodolfo Rabanal, Probibido escupir sangre de Guillermo Saccomano y Apuestas de Andrés Rivera), no solo obedece a su carácter comprehensivo, sino que tiene el sentido (en todo caso este es el efecto que produce) de, por un lado, subrayar en ese ensayo de 1987 el carácter inaugural de un modo de leer la relación de la narrativa argentina con el presente (con el presente político inmediato) y de, por otro, trazar una parábola, la de la articulación entre la propia lectura y el presente de sus objetos, que se resignifica, o que adquiere su cabal significación, desde las dos polémicas intervenciones de 2005 y 2006, “¿Pornografía o fashion?” y “La novela después de la historia. Sujetos y tecnologías", con las que Sarlo cierra la sección, y el libro. ${ }^{3}$

La parábola, sin embargo, no solo distribuye en sus extremos corpus y coyunturas históricas de evidente contraste: de un lado, un conjunto de novelas escritas y publicadas entre 1976 y 1985, cuando la gravedad de la historia "imantó el espacio de los discursos" e impulsó a la narración a inventar nuevas formas de representación y a ensayar modos oblicuos de interrogar el pasado y figurar críticamente el presente; del otro, unas novelas publicadas entre 2004 y 2006 (kerés coger? = guan tu fak? de Alejandro López, ¿Vos me querés a mi? de Romina Paula, Cosas de negros y Las aventuras del Sr. Maiz de Washington Cucurto, La ansiedad de Daniel Link), suficiente muestrario del modo en el que, una vez que la literatura ocupa otro lugar en la circulación pública de los discursos, una línea de la "novela actual" hace del tiempo presente predominante en sus historias no ya un enigma a resolver, sino un mero escenario de "tribus y dialectos urbanos" a representar, al modo de una documentación "etnográfica" tan festiva y bienpensante como plana y sin distancias. La parábola, decía, no solo distribuye una disyunción conceptual: historia-etnografía. Muestra además, y sobre todo, que lo que se ha modificado para Sarlo al cabo de esos veinte años, junto con el lugar y el valor del presente en la literatura (materia de una elaboración formal y de un contenido que hay que representar), es el lugar y la función misma de la crítica en relación con el presente de esa literatura: de la formulación programática de una crítica literaria que en 1987 se reconoce articulada con una preocupación ética y política sobre la historia 
reciente del país y que se emprende "con la esperanza de reencontrar un lugar que desborde los límites de la institución literaria, para ponerse en relación con instancias de significatividad social más extensa" "Política” 327), se pasa a una intervención que, en el contexto de los debates sobre literatura y posautonomía, se entiende ahora como una apuesta fuerte por "sostener" y "discutir" (tales son los términos que cierran las intervenciones de 2005 y 2006) la vigencia y el valor de los presupuestos estéticos. Como si el aumento en el "peso" del presente como "contenido" literario afectara a la práctica crítica, reorientándola hacia el terreno de un debate de orden prioritariamente estético; por lo demás, según una especificidad institucional de la que veinte años antes había querido salirse. De modo tal que la discusión se plantea ahora en términos de una defensa de la legitimidad de la lectura en términos de apreciación de valor (esto es, una refutación de la idea de que, en el contexto de la expansión de los límites literarios, no tiene ya sentido la evaluación de unos "resultados estéticos" por su calidad). Sarlo esgrime, como volviendo a las herramientas propias de la crítica literaria, categorías como idea de composición y perspectiva formalista, y se entabla, además, no solo con unas novelas en particular, sino, sobre todo, con un modo de leer en principio ampliamente consensuado en esa red de lecturas y juicios valorativos que constituyen el campo literario.

Cuando se publicaron en Punto de Vista “¿Pornografía o fashion?” y "La novela después de la historia”, casi en simultáneo con las también polémicas intervenciones que Josefina Ludmer publicó en la web entre 2006 y 2007 bajo el título de "Literaturas posautónomas", ensayé algunos argumentos y preguntas para tratar de pensar las operaciones, pero también los límites de lo que experimenté de inmediato (en particular a partir de la lectura que Sarlo hacía de Cosas de negros y Las aventuras del Sr. Maiz de Washington Cucurto) cierta resistencia a las formas propias del presente. Una de las hipótesis decía que tanto el énfasis puesto en el término etnografía, en un sentido devaluado, como su elección en detrimento de ese término clásico y recurrente para impugnar la mímesis banal de lo real, como lo fue siempre - en la crítica de Sarlo- el término de costumbrismo, mostraba no solo una estrategia para aplanar como turística toda narrativa que representara sin distancia crítica las comunidades del mundo contemporáneo, sino también el modo en que, sutil pero definitivamente, esas comunidades parecían volverse, para la propia Sarlo, los "otros" del lector: ajenos, extraños y hasta incomprensibles. Una de las preguntas apuntaba, en este sentido, a apreciar cuánto la resistencia a las formas del presente convertía a la apuesta por el valor estético en prescriptiva, cuánto esa resistencia convertía a las categorías de la modernidad crítica en valores del pasado, cerrados a la dialéctica misma del presente, o, si se quiere, de la modernidad (véase Contreras). No volveré aquí sobre esas hipótesis; las tomaré, sin embargo, como presupuesto para pensar ahora la sintaxis argumentativa, digamos de larga duración, desde la que se podrán releer los movimientos, si se quiere implícitos, del ensayo que ahora perciben esa crítica a la "regresión estética" de la "novela actual".

La modificación en la lógica del mapa del presente es uno de los índices. Anclado fuertemente en las poéticas que confluyeron en el programa estético de Punto de Vista (como sabemos, las de Saer, Piglia, Rivera, Tizón, Martini, entre otras), pero incluyendo también escritores con los que ese programa podría marcar sus diferencias (Jorge Asís, por ejemplo), el corpus de 1987 postula un mapa que distribuye literaturas diferentes, y hasta opuestas, estética e ideológicamente, a partir de la premisa de que, desde Respiración artificial hasta Flores robadas en los jardines de Quilmes, un mismo problema las "atraviesa" a todas: "Aproximar respuestas, a menudo altamente figuradas, a la pregunta sobre la historia argentina y las experiencias de los últimos años" ("Políticas" 335). ${ }^{4}$ El mapa de 1987 es integrador en el reparto y proclive a la conciliación. Después del contundente desafío estético con que cierra “¿Pornografía o fashion?”, en 2005, el mapa ampliado con el que abre el ensayo del año siguiente, "La novela después de la historia", busca dar cuenta de las razones que puedan explicar por qué la narrativa escrita en los años noventa y dos mil, aún cuando se interese o ensaye variaciones sobre los años setenta (tal es el caso de algunas novelas de Luis Gusmán, Carlos Gamerro, Sergio Chejfec, Martín Kohan), no tiene ya, como la novela de los ochenta, a la clave interpretativa como eje de la ficción. Esas explicaciones dicen que la violencia de la historia reciente ha recibido ya explicaciones "mejores y más específicas" que las que la literatura, cuando "faltaba discurso social", elaboraba en solitario; y es en ese 
contexto que Sarlo sitúa, casi como el corolario de ese tránsito de veinticinco años, la emergencia de una línea visible de la novela actual, como es la etnográfica, y que será aquí su objeto ("La novela después" 473). Sin embargo, y aún cuando Sarlo quiera manifestar de entrada que "no se trata de clasificar libros en un par de columnas" ("La novela después" 474), el mapa que importa en el ensayo de 2006 es el que, para confrontar el registro plano "sumergido" y tecnológico de las novelas de Paula, Cucurto y Link, recurre a la "etnografía hipotética" de Los pichiciegos de Fogwill y a la "imaginación etnográfica" de La villa y Las noches de Flores de César Aira, para llamar la atención sobre la forma en que, sea en 1983, en el 2001 o en el 2004, unas novelas que también proponen miradas documentales del presente más coyuntural "se socavan a sí mismas en los tercios finales, desmintiendo su etnografía” y reorientan, a través de torsiones desrealizadoras, su potencial documental hacia otra dimensión ("La novela después" 475).

El recurso al Fogwill de Los pichiciegos y al Aira de los años 2000, que Sarlo presenta ahora en 2006 como una referencia a "dos escritores que vienen de los ochenta" y que "son fundamentales" ("La novela después" 474), interesa, creo, en dos sentidos. Por una parte, vale la pena observar que estaba muy próxima la lectura de La experiencia sensible, una novela clave para Sarlo, precisamente por su altísima capacidad para mostrar cómo la vuelta al realismo que profesa su prólogo obtiene toda su legitimidad del modo en que, con la dosis justa de ironía y con la conciencia necesaria del fracaso, Fogwill acomete el acto reconstructivo de un pasado muy próximo, mientras encuentra claves significativas de uno de los periodos más degradados de la sociedad argentina (el del neoliberalismo de los años noventa que hunde sus raíces en la dictadura). Que ese conocimiento crítico del presente, a resguardo de todo mimetismo banal y de todo moralismo pedagógico, siga encontrando una singularísima resolución formal en un retorno al realismo que en el año 2001 se anuncia tan anacrónico como fantasmal, desde luego, no hace más que potenciar para Sarlo el valor de la novela y su programa estético en el contexto de la literatura argentina del presente (véase Sarlo, "Sueño"). ${ }^{5}$ Sin embargo, y resulta curioso, para situar la línea etnográfica de la novela actual en su mapa del 2006 Sarlo prefiere pasar por alto esa variante legítima del realismo contemporáneo para poner el foco en la confrontación con una novela que, mientras tenía lugar la guerra de Malvinas, llevó al extremo el desafío de articular etnografía (mirada documental del presente inmediato, urgente hiperrealismo) e interpretación (carácter imaginario e hipotético de la situación). El recurso a La villa y Las noches de Flores es todavía más interesante. No solo porque se trata del primer análisis que Sarlo le dedica, en 2006, a unas novelas de Aira, sino porque después de veinte años en los que, aun cuando la cuestión fuera "leer en presente", su literatura dejó de ser objeto de atención en las páginas de Punto de Vista, su retorno resulta, por el contexto del debate en el que se produce, por cierto, espectacular. ${ }^{6}$ En rigor, Sarlo se había remitido al nombre de Aira ya en el artículo de 2005 en el que, para liquidar la "pornografía cool" y la "high fidelity etnográfica" de Kerés cojer?=guan tu fak, cierra con tres citas de Vivir afuera (Fogwill), Las noches de Flores (Aira) y Glosa (Saer), tres novelas en las que, sustrayéndose al lugar común, la narración del sexo produce el shock propio de la distancia estética. De modo tal que, no obstante el repliegue en la valoración que nosotros podamos percibir cuando en el apartado siguiente le atribuye "amenidad" y "diversión", 7 en la lectura que en 2006 Sarlo hace de la "maestría" con que Aira resuelve el "abandono de la trama" (y este es el subtítulo del apartado que le dedica en el ensayo) resuena el notable gesto previo de haberlo convocado como parámetro de valor, y nada menos que del lado de Saer, para confrontarlo con una novela "actual" tan tediosa como superficial.

Como se ve, los mapas del 2005 y 2006 ya no reparten, sino que deslindan, oponen, confrontan. Es cierto que el ethos valorativo en que se funda la práctica crítica de Sarlo opera a menudo por contraste; más aún, de ascendencia tan adorniana como barthesiana y también borgiana, pero sobre todo definida desde la vanguardia estética y política de nuestros años sesenta, la confrontación con el realismo (en tanto mímesis banal) y con el costumbrismo (en tanto registro plano de la tipicidad), como con un espejo negativo desde el que apreciar las resoluciones formales que se les "resisten", es precisamente una operación crítica constante cuando se trata de "leer en presente". 8 No menos cierto, sin embargo, es que nunca, como en las argumentaciones de 2005 y 2006, Sarlo había echado mano a una serie de nombres propios para erigirlos, en 
el espacio delimitado del ensayo, como resoluciones formales ejemplares en desmedro de otras con las que quiere discutir. Nunca tampoco, si no me equivoco, se había detenido tan extensamente en describir, inclusive en tratar de desentrañar, compositivamente hablando, una literatura a la que se le reprocha (el término es de Sarlo) sus opciones y resultados estéticos. ${ }^{9}$ El gesto es tan filoso que ahora, excediendo el acto de clasificar, hace visible, estrecha y lleva al extremo de la confrontación.

¿Qué es lo que afecta de tal modo una sensibilidad crítica que hizo siempre de la polémica, del debate intelectual y de la discusión estética, un modo de pensar? ¿Qué fuerza puede empujar a ese pensamiento a alterar la lógica del mapa y a inclinar los modos de decir del ensayo hacia la irritación? ¿Nada más el encuentro con una literatura "otra", que se le vuelve inverosímil desde el punto de vista compositivo y reprochable desde el punto de vista estético? ¿ O se trata, más bien, del encuentro — del choque- con un modo de leer? Dice Sarlo: "El presente etnográficamente registrado es elegido por novelas que son leídas como 'lo nuevo' de la literatura argentina" ("La novela después" 473). Y creo que, aún cuando no identifique a sus interlocutores (porque no es una polémica de este tipo la que le interesa entablar aquí), es precisamente ese modo de hablar y de entenderse (otros) en relación con la literatura del presente, es ese estado de la lectura, más que de la literatura como "iconografía de lo Actual", el que se ha convertido para Sarlo, quizás por primera vez de forma tan reflexiva y sistemática, en el ruido de la actualidad. Esas comillas lo subrayan.

En 1988, Sarlo publica en Elnuevoperiodista un artículo que titula "Ficciones del saber" y en el que se ocupa de los "tiempos" de las literaturas de Piglia y de Saer; esto es, del tiempo que a cada una le llevó encontrarse con sus lectores. La edición de Escritos sobre literatura argentina lo incluye a continuación de "Política, ideología y figuración literario", el ensayo — dijimos inaugural- de 1987. Dice allí: "A la literatura de Saer nadie la esperaba"; Respiración artificial, en cambio, "demostró inmediatamente después de aparecer en 1980 que allí estaban los lectores o, en todo caso, que la novela podía producirlos” (“Ficciones del saber” 356). ¿Y qué es lo que para Sarlo explica esa "inmediatez"? El hecho de que, así como Renzi y Tardewsky exponen ante sus oyentes todos los temas que preocupan al intelectual y a su público, así, la novela está construida con "la materia [densa] de las conversaciones intelectuales sobre literatura, política, historia de las ideas, filosofía, los avatares de la razón occidental y de la historia argentina" ("Ficciones del saber" 356). Esto es, así, la novela de Piglia está hecha con el presente de una conversación social: el pasado puede ser el tema y el tiempo del relato, pero el presente es el tiempo de un estado (social) de la lectura.

El presente, entonces, como el ámbito de una conversación social. Un conjunto de tópicos, sí, pero en estado de conversación, y un conjunto de implícitos o sobreentendidos. Esto es, una lengua. En este sentido, la pregunta que moviliza la discusión de Sarlo con la etnografía actual sería no tanto ¿con qué temas?, sino ¿con qué conversaciones, con qué implícitos, se escriben y se leen las ficciones del presente? Si, como ya observó Judith Podlubne, en la critica cultural de Sarlo el interés por el presente es indisociable de una preocupación por los estilos de intervención y sus condiciones de "audibilidad" (68), si "la eficacia del discurso crítico gana su primer batalla en la adecuación de la distancia 'intelectual y moral' que lo define, con los patrones de discusión previamente establecidos por consenso" (69) y la lengua "capaz de resultar audible" en el debate es por esto la de la escucha y el diálogo que viven de una distancia media de "intermediación" (70), ${ }^{10}$ los ensayos de 2005 y 2006 muestran cuánto la crítica literaria, cuando su objeto es la literatura del presente, se expone a, y se debate con, el malentendido - pero al modo de un choque sin mediación entre dos lenguas extranjeras - cuando ha cambiado el tema, y la forma, de la conversación. ${ }^{11}$

Entre paréntesis, pero como un rodeo que me resulta necesario, diría aquí que el énfasis puesto en el término etnografía podría estar expresando también el filo por el que el problema estético y político del realismo, tal como fue fundado en los años sesenta y reactualizado por Sarlo y Punto de Vista en los ochenta, cruzó un límite hacia otro lugar. Me refiero al modo en que, tal como puede percibirse sobre todo en el pasaje de "¿Pornografía ofashion?" a "La novela después de la historia", ya no solo se trata de objetar un exceso de mímesis sin distancia crítica (el "viaje turístico por el país de los monstruos" de la etnografía actual, del mismo modo en que siempre se impugnó el "color local” del costumbrismo), de señalar un exceso que redunda en inverosimilitud por falta 
de invención (tal, el objeto del reproche estético a la novela de Alejandro López en la excelente fórmula que dice: "Lo inverosímil es déficit de la invención"). Se trata, ahora - y en especial a partir de la lectura de las novelas de Cucurto-, de ensayar criterios para evaluar una nueva modalidad del exceso que Sarlo empieza a medir en formas de un "desenfreno" que afecta a la literatura "actual" en su verosimilitud formal. Quiero decir: ante las variantes etnográficas del presente, Sarlo plantea ahora el problema del realismo en términos de verosimil, pero de verosímil compositivo, en función de la sintaxis del relato. En este sentido, puedo ver ahora que el apartado dedicado especialmente a César Aira viene precisamente a decir que solo cuando se expresa un cansancio (contemporáneo y genuino) de la ficción y se resuelve con maestría una forma propia para el desenlace inconclusivo (Sarlo le da el nombre de "maravilloso disparatado"), solo cuando para la crítica son evidentes las razones estéticas y epocales que lo fundan, el abandono de la trama se convierte en arte y se revela, por consiguiente - aun en las novelas-crónicas del presente coyuntural—, como la "impugnación más severa de la ilusión representativa" ("La novela después" 475-476). Y, entonces, al lado del "abandono de la trama" como herramienta compositiva de la etnografía "buena", la indiferencia de Cucurto a la sintaxis, articulada en sus relatos en un lenguaje sin límites ("todo pasa azarosamente" y "se puede decir todo"), es, en cambio, el camino más rápido hacia el tedio y hacia el fastidio (porque es el tedio ante la banalidad) en la lectura; y el aburrimiento, el de la lectora y ya no el del escritor, es el signo más palmario de las fuerzas que afectan a la crítica en el presente. La inclusión en Escritos sobre literatura argentina del hermoso ensayo sobre La hija de Kheops, que Sarlo mantuvo inédito desde que lo escribió en el mismo año de publicación de la novela, aunque seguramente no fue pensado de este modo, produce en el volumen el efecto de mostrar que, aun cuando hoy pueda señalar la ausencia de escándalo en la "sana diversión, desfachatez y simpatía" de Cucurto, en la historia de sus lecturas la suya no es una crítica per se reactiva al "exotismo" en las novelas, ni siquiera a las novelas de "tono feliz", porque, por el contrario, su inclinación a disfrutar de una novela de entretenimiento y, al mismo, tiempo filosófica (cuando propone, como esta, el ideal social de una humanidad reconciliada con la trascendencia) la invita inclusive a prescindir de clisés que no la convencen (como el del "realismo delirante de aventuras") para inventar en su lugar fórmulas perfectas (así "el utopismo delirante retrospectivo") con las que, mientras habla en la misma lengua que Laiseca, celebra y potencia la capacidad inventiva de su literatura. ${ }^{12}$

En este sentido, además del parámetro del realismo que pondera el grado de verosimilitud de la invención, la lengua —el uso de la(s) lengua(s) — es la segunda gran variable en la evaluación de las potencias y legitimidades de las literaturas del presente. ¿Qué lengua puede hablar la literatura? Una pregunta clásica, que Sarlo postula como fundante de la literatura nacional y que hoy sigue formulando como decisiva para leer las ficciones argentinas: ¿con qué lengua es legítimo escribir ${ }^{13}$ La respuesta no está solo, por la negativa, en la discusión con el "narrador sumergido" de Cucurto; está también, y sobre todo, en la lectura de los años noventa de Diálogos en los patios rojos y de Si hubiéramos vivido abí, que dice que si hay algo que mide la originalidad y lo inaudito de la lengua de Roberto Raschella, es la forma en la que su prosa "pausada, sentenciosa y firme" incrusta el calabrés en el español, pero al modo de "altorrelieves sólidos", sin nada que recuerde "la lengua colorida pero caricaturesca del cocoliche" ("Lugar de origen" 404-405). También dice que su uso "ilimitado" y "anarquista" del lenguaje es indisociable de una lengua en la que, aun cuando "todo esté molestando al castellano rioplatense" y "todo esté fuera de lugar", en realidad, y esta es la convicción primera y profunda en el ensayo, "nada está fuera de lugar" ("Experiencia” 401).

$\mathrm{Al}$ otro lado del anarquismo lingüístico de Raschella, la lengua hiperbólica de Cucurto es, implícitamente para Sarlo, la de un escritor "fuera de lugar". Pero no solo porque esa lengua celebra con cuerpos "cumbienteros" la ridícula "alegría de vivir", no solo porque "abandona toda cautela entre lo que puede y no puede decirse" en un relato que, indiferente a la sintaxis, declina la ilación ("La novela después” 478-479), sino porque, además, tal vez como caso testigo de la literatura del presente, el movimiento ensayístico de Sarlo muestra a la literatura que se escribe con esa lengua confrontándose con una incapacidad que diríamos superior — casi total - para resistir la prueba de la biblioteca argentina. Y es que la lengua de la crítica, como un conjunto de implícitos, es también para Sarlo el "espacio cultivado" de la biblioteca, el sistema de 
nombres propios, como el terreno por el que siempre transita la lectura, apoyándose firme en un reaseguro de resonancias.

"Un escritor — dice Sarlo cuando lee a Piglia— escribe nombres propios: Kafka, Joyce, Hitler, Sarmiento, Rosas, Arlt, Borges. El nombre propio es un anclaje fuerte del reconocimiento, traza una red de significados sobre los cuales el debate de ideas es posible" ("Ficciones del saber" 356). La lengua común de la biblioteca, entonces, como garantía de un entendimiento en el debate; también como la mejor herramienta de esa "voluntad de saber" que para Sarlo siempre impulsa a la indagación crítica. ${ }^{14}$ Su incidencia es decisiva en la lectura del presente. La vemos funcionar como el horizonte desde el cual capta pero también busca explicar cada vez la "novedad" del presente: así, los capitales ensayos sobre Sergio Chejfec que - dice- escribe para "explicar[s]e a [s]í misma" la "sorprendente y a veces inexplicable originalidad" de una sintaxis que se fue inventando a medida que se iba desligando de las "influencias más evidentes, de Saer a Bernhard" (394). ${ }^{15}$ También, al modo de un filtro para lo insólito y de una contención para la desmesura: así, la "exageración y extravagancia" de La historia, la monumental novela de Martín Caparrós, no como déficit, sino como la forma inevitable de una imaginación narrativa y lingüística que es producto de una "alianza de habilidades librescas y fantasía despótica" y que solo se puede ejercer con una "masa de lecturas" que aquí son "el medio mismo de la ficción” (445). O como el motor del placer con que se lee el manuscrito de El coloquio y que se afirma, en gran medida, en el tipo de legibilidad que asegura un relato, como este de Alan Pauls, "inconsumible":

Me gustan los nombres de los personajes: Brod, Werfel, Mossalini, el doctor Kalewska, Greta V., Longhi, Bertoldo. Me remiten al mismo tiempo a Praga, Viena, la república de Weimar, las novelas de Kafka, los apellidos que usa Thomas Mann, los nombres de los pacientes de Freud. ("Un relato" 442)

Pues bien: a Washington Cucurto no se lo priva de ese tránsito; por el contrario, el ensayo lo remite a cada paso a una multiplicidad de nombres propios, solo que, para comprobar, cada vez, que ni intelectual como Saer, Piglia o Chejfec, ni crítico en el uso de las lenguas bajas como Arlt o Puig, ni transgresor del realismo pequeñoburgués y bienpensante como Lamborghini, ni dandi elegante en el abandono de la trama como Aira, su literatura cae, por todos los costados, fuera del sistema de referencias familiares que podría connotarla. Desde luego, el exceso que interesa es el del ensayo mismo de Sarlo, que, menos con Borges, rodea a Cucurto con todos los nombres de la literatura argentina, mostrando, en ese inédito tratamiento excesivo (siete cotejos en el apretado espacio de dos páginas), todo lo ajena - lo extranjera - que esta narrativa le resulta contra el fondo de una tradición que le garantiza legibilidad (una lengua) y de una historia de la literatura que le asegura un saber (un mapa). ${ }^{16}$

El último gesto del ensayo de 2006, con el que cierra la sección "Leer en presente" y Escritos sobre literatura argentina es, creo, elocuente. Si los libros de Cucurto, Paula o Link — dice Sarlo- tienen un aire de familia, lo tendrán con el rasgo documental del arte contemporáneo; si hacen sistema, lo harán con "el arte del mensaje bajo sus formas contemporáneas" ("La novela después" 481). Un modo de decir que, si "estas notas se han referido tanto a la literatura argentina como al giro documental del arte, un capítulo abierto en paralelo a la crisis de las interpretaciones" ("La novela después" 482), es porque, mientras se insiste en discutir en términos de presupuestos estéticos, la lengua de la literatura argentina "actual" ya se tradujo (ya se desplazó) a otro lenguaje (el del arte y su agenda) y a un orden temporal (probablemente debamos decir también a un espacio) más amplio y también más distante: el tiempo de lo contemporáneo, que para Sarlo siempre es menos argentino que global.

\section{Exploraciones}

Resuelta de este modo la discusión con los protocolos contemporáneos de la crítica, o bien, dando por interrumpida una conversación que ya se había convertido en otra, Sarlo reinicia, en 2007, un diálogo 
con la literatura argentina del presente que, sin deshacerse de los presupuestos recientemente reafirmados, adopta, sin embargo, tal como lo define en el prólogo de Ficciones argentinas, la nueva forma de un viaje exploratorio. Su primera gran premisa es, precisamente, el abandono del mapa, de su guía, pero, sobre todo, del imperativo de trazarlo, de proceder al ordenamiento y la clasificación. ${ }^{17} \mathrm{El}$ formato más apto, naturalmente, es el periodístico: la columna periódica, la estructura de la anotación, el estilo de diario de lecturas. Su efecto, en la lectura retrospectiva que se hace para prologar la reunión de los ensayos en 2012, es una reorientación en el vocabulario de la crítica que, liberándose de la constricción institucional de la historia literaria (la de la crítica académica y el problema del canon, pero también la del mercado), parece ahora mezclar libremente las ideas de "presente", "actual" y "contemporáneo":

La crítica vive en la actualidad, no en la historia literaria. Cuando se interesa por el pasado, mantiene esa misma vibración que caracteriza su relación con lo contemporáneo: lee a los que se pasó por alto, reinterpreta. Pero el suelo de la crítica es el presente. Le interesan los escritores de los que es contemporánea y quiere entender lo que sucede con ellos y con lo que escriben en el momento. Establece una relación con el texto, lo más íntima que sea posible. El canon, en cambio, resulta de una inversión a plazos, en un campo de fuerzas e intereses institucionales y mercantiles. (Ficciones argentinas 13)

Una nueva ética crítica, podría decirse, cuyo mayor desafío proviene de la expresa adopción (o reasunción) de un impulso barthesiano con el que, fundándose nada más que en el gusto subjetivo y en la inmediatez del interés, apuesta ahora a la singularidad del encuentro en la lectura: "Escribir al toque, incluso sobre autores que conozco bien. No girar sobre un capital depositado, sino ver qué dice cada uno esta vez, en este nuevo libro" (Ficciones argentinas 12; cursivas propias).

Sus efectos podrían situarse, en principio, en cierta acentuación de aquella perspectiva formalista que reivindicaron sus intervenciones de 2005 y 2006, y que aquí Sarlo exhibe con brillo en el oficio: pericia en el análisis técnico que fluye con firmeza entre los diversos planos del relato, sobre todo en la lectura de los autores "nuevos", cuando busca desentrañar de cero su principio compositivo (véase, por ejemplo, "Objeto sólido e inestable" sobre Hélice, de Gonzalo Castro, o "Vivir para leer, leer para escribir" sobre En la pausa, de Diego Meret); predominio de abordajes al estilo de "cómo está hecho" (véase, por ejemplo, "El Rolex de Aira", sobre Las conversaciones, una "fábula teórica" que a Sarlo le resulta ideal para volver a pensar la articulación entre delirio y verosimilitud en la singular composición airiana); redefinición de categorías y géneros, como la interesante redefinición de la estética de "lo plano" a partir de La hora de los monos de Federico Falco (en un sentido tan diverso al del deficiente registro plano de Romina Paula) ${ }^{18}$ o el retorno al quantum de transgresión que tanto la había decepcionado en la pornografía fashion de Alejandro López, y que ahora le permite leer en clave de gore explícito los cuentos de terror de Mariana Enríquez, o en clave de cold porno Los daños materiales de Matilde Sánchez; ${ }^{19}$ y, sobre todo, pulsión de argumentar con exactitud y rigor el gusto por esas cualidades de la perfección que para Sarlo son, especialmente, la inteligencia (así titula la relectura, a veinte años de su primera edición, de La ingratitud de Matilde Sánchez) ${ }^{20}$ y la obstinación (así titula el ensayo sobre La experiencia dramática de Sergio Chejfec, testimonio único y asordinado de la afirmación, barthesiana recuerda Sarlo, de lo irreductible literario). ${ }^{21}$

Pero, si ese renovado impulso barthesiano se traduce, en principio, en una exploración del presente que se quiere liberada de la presión del mapa y de la historia (uno de los ensayos se titula justamente "Leer sin referencias"), es notable a la vez cómo la biblioteca retorna, aunque según otros énfasis, en la lengua de la crítica. Y es que aun cuando quien ahora escribe es una lectora dispuesta al encuentro "por primera vez" con un texto, como quien se aventura en un "terreno incierto" ("Leer sin referencias" 15), sin "bibliografía" y sin consensos previos (y el subrayado de ese "riesgo" es signo de su vértigo), aun así la búsqueda de ese nombre propio que "autoriza, hace visible [y] le proporciona contraseñas a una ficción" ("Ficciones del saber" 356) sigue reconociéndose, una y otra vez, como una herramienta clave para vérselas con la novedad. No tanto, sin embargo, cuando la crítica se debate con el temor a ser tomada "desprevenida" por "no saber", sino cuando el elenco de nombres propios aparece, libremente, bajo la forma de resonancias que promueven relecturas, en la 
llegada de recuerdos aleatorios y hasta descartables, o en el modo de afinidades y coincidencias que, como el eco de la literatura de Chejfec en la de Oliverio Coelho o las huellas de la de Saer en la de Hernán Ronsino, confirman que una literatura "no es nada más que un depósito de novedades". 22

En este sentido, la lectura de El viento que arrasa, de Selva Almada, es la expresión máxima de un modo de exponerse ahora a lo inesperado del presente. El título del ensayo es "Fin del mundo" y su primera línea dice así: “¿De dónde salió este libro sorprendente?” (201). La conmoción del hallazgo es tal que, de inmediato y precisamente porque se trata de un "objeto insólito" - pero "en la literatura argentina”-, esto es, en un sistema, en una historia, se impone la pulsión por buscar "aires de familia” (la extrañeza de Jorge Consiglio, la excentricidad de Saer, el aire de provincia de Carson McCullers) que provean la lengua con la que empezar a hablar. La lectura ya no necesita del mapa crítico para localizar(se), pero sí de una lengua de ecos y resonancias que (la) oriente. Lo cual no quiere decir, sino que la pasión crítica sigue estando, sin duda, en la lengua del presente. Por esto mismo, no podría pasarse por alto el otro punto de conmoción en el itinerario del volumen; el título del ensayo es "El imitador de voces" y comienza así:

Vacilé antes de escribir esta nota porque vuelvo a plantearme en qué está la Argentina. No qué escriben Chejfec, Kohan, Pauls, Guebel o Aira; tampoco qué escribieron Saer y Fogwill, sino cuál es el efecto que produce la literatura de estos últimos años, aunque sea probablemente injusto con cada uno de los escritores, incluso con algunos sobre los que yo misma he escrito. Como todo efecto, proviene del recuerdo de decenas de libros y de la acumulación de impresiones. Frente a Pinamar, la novela de Hernán Vanoli, me pregunto: ¿qué quiso hacer el autor? (171)

La vacilación, producto de la extranjería que se experimenta ante una nueva versión del hiperrealismo lingüístico (otra vez, la imitación literaria de las lenguas del presente, pero llevada al límite de una ocupación masiva del relato y de un borramiento de todo narrador exterior al personaje), es lo que me interesa. De ella se sigue una reescritura de las intervenciones de 2005 y 2006 que, ahora más teórica que confrontativa, funciona en el conjunto como un pivote en torno del cual gira la renovada apuesta por una opción constitutiva: esa literatura que, "lejos de las ondas" y sin exhibir la proliferación de multiculturalismo que hoy suele aparecer bajo la forma de un gusto exagerado por lo bizarro y lo colorido-marginal, ensaya, con medios tonos y a la distancia justa, un realismo de la dislocación que, como el de Jorge Consiglio, "tiene algo de excavación en el tiempo" ("Luminosa oscuridad" 187) o que, como el de Eduardo Muslip, sabe ser "familiar en lo extranjero" ("Phoenix, lejos del centro" 97).

Aunque no se sepa muy bien de dónde procede (y en la desorientación que produce radica gran parte de su encanto), la novela de Almada trae algo más. Y es que, si el multiculturalismo de hoy es el de una agenda que para Sarlo es ante todo global (su ley es la del mercado, el de la academia o el del arte contemporáneo), El viento que arrasa le da forma a una literatura regional, allí mismo donde, indiferente a los "viejos realismos" del presente, inventa, conciso y sobrio, un tono nunca antes escuchado en la ficción argentina. Por eso mismo, porque "la originalidad de una ficción siempre se juega en la lengua" ("Fin del mundo" 202) y porque frente a las culturas globales de la actualidad inesperadamente redescubre las potencialidades de lo regional, es una "novela de hoy" ("Fin del mundo" 205).

\section{Zoom}

El arco que va de "Política, ideología y figuración literaria" a "La novela después de la historia" es una parábola que - decía- Sarlo inscribe como tal en 2007, retrospectivamente, cuando edita el volumen Escritos sobre literatura argentina. Y es desde esta mirada retrospectiva que la literatura de Juan José Saer, que atravesó todo ese cuarto de siglo de lecturas, pero que, sobre todo, fue su más estricto "contemporáneo" (la lengua misma en la que habló), es desplazada de la sección "Leer en presente" para decir que, más que de lo inmediato, su tiempo es el de los clásicos. ${ }^{23}$ 
En ese sentido, del mismo modo en que María Teresa Gramuglio lo argumentó tempranamente, en su ensayo de 1984, la idea de que Saer tuvo un reconocimiento tardío es un leitmotiv en la crítica de Sarlo. Pero esa tardanza, que desde el punto de vista de la institución es reconocida una y otra vez como una injusta postergación (de la sanción de la crítica, del canon y también del mercado), desde otro ángulo, uno en el que se sitúa la lectora, más que la historiadora, se experimenta como todo ese tiempo que la fuerza contenida en la originalidad de su literatura necesitó para ser pensada ("Una poética” 307). La lectura de Sarlo trabaja en este anacronismo saeriano. No tanto cuando, según la lógica temporal de las instituciones, le asigna en el libro el gran lugar que le corresponde en la historia de la literatura argentina, sino cuando la escritura de la ensayista, en implicación íntima con una literatura que ama, se deja atravesar por huecos y retornos diversos y se afecta, digamos, de un anacronismo constitutivo.

En el nudo de ese tiempo extenso (la espacialidad del tiempo es de índole saeriana) está Nadie nada nunca. Entre la captación inmediata, en la pionera lectura de 1980, de la novela como una teoría del presente (en el principio, diríamos, está el presente como un "estado de la ficción”) y de la interpretación, que podrá hacer recién en 1987, de su relato como una cifra de la violencia del presente (pero ahora del presente político); entre el descubrimiento de la "condición mortal" de los personajes (descubrimiento retrasado del orden de un impacto que la fuerza a revisar esa novela y también la obra entera y la historia misma de su lectura) y el retorno en 2016, una vez más, a la lectura de 1980, para apreciar ahora cabalmente en qué sentido y con qué alcances Saer se separaba del realismo; entre una y otra vuelta en torno de Nadie nada nunca, el vínculo de Sarlo con la literatura de Saer y con su tiempo se entabla al modo de un lazo con el presente que, social y subjetivo a la vez, se experimenta en estado de afección: "Recordar (releer) Nadie nada nunca, implica, después de Glosa, un saber sobre el Gato y Elisa que no puede dejar de afectarnos" ("La condición” 293). ${ }^{24}$

Lo que subyace en ese retorno periódico y en esa afección profunda es el encuentro con la "realidad" de la "condición mortal". Se trata, claro, de una realidad literaria — la de los personajes_, pero que Sarlo experimenta — que a Sarlo le gusta decir que experimenta - al modo de una lectora del siglo XIX, finalmente realista, como si fuera una condición real. Los efectos de esa implicación son de largo alcance: así como el último retorno se ensaya, ahora sí fuera de todo imperativo institucional, con la única pulsión de dejar testimonio de "la felicidad y el asombro que siempre sint[ió] por la literatura de Saer" ("Sujetos" 9) y para eso elige colocarse bajo los auspicios de un auténtico recomienzo (el desafío es hacerlo de cero, sin volver a lo ya escrito), así también, según una preciosa lección sobre las transmutaciones de la crítica cuando esta se emprende bajo los efectos de un impulso vital, es notable cómo el realismo, transfigurado ahora como un "modo de leer", va ganando terreno en Zona Saer: ese "mundo material" que tanto le interesaba al escritor (espacios, comidas, conversaciones), va ocupando, hacia el final, la escritura de la crítica. De modo tal que, si el libro comienza con un mapa ampliado, el de la historia literaria, donde se puede situar una vez más la emergencia de un "escritor descomunal" al "margen de todo", cierra, en cambio, con unos mapas cuya utilidad dice haber aprendido en los libros de Franco Moretti, pero que son los que investiga, se afana en precisar, y agranda, una crítica cautivada ya por el realismo en la lectura. Del mapa trazado con el telescopio de la historia literaria al mapa que hace zoom sobre los recorridos de los personajes entre las calles de Santa Fe y de Rincón, la parábola es equivalente, podría decirse, a la que va de la distancia crítica, signo mismo de la mejor literatura, al placer de la inmersión, del lado de la lectura, en esa "materialidad externa" que Saer siempre evitó representar, pero de la que se valió, como "coordenadas realmente existentes", para construir su zona (Zona Saer 117). Sucede, además, que la reconstrucción de esos tres mapas finales, que Sarlo emprende con la ayuda entusiasta de Roberto Maurer, devuelve a Saer a un tiempo heterogéneo al de los debates del presente, sean estos los de la crítica cultural o los de la crítica literaria: un presente social, siempre que esa sociedad sea la de una comunidad cultivada en la conversación como cultura de la amistad; y un presente subjetivo, hecho de reminiscencias y redescubrimientos en los que está implicada una vida, con la curiosidad intacta. Resulta, por cierto, interesante que Sarlo interrumpa su contemporaneidad con Saer en este punto del tiempo y del espacio. 


\section{Referencias}

Balderston, et al. Ficción y política. La narrativa argentina durante proceso militar. Alianza Estudio, 1987.

Barthes, Roland. Cómo vivir juntos. Siglo XXI, 2003.

Barthes, Roland. La preparación de la novela. Traducido por Patricia Willson Siglo XXI, 2005.

Catelli, Nora. "Los gestos de la posmodernidad". Punto de Vista, n. ${ }^{\circ} 22$, diciembre de 1984, p. 37.

Contreras, Sandra. "En torno a las lecturas del presente". Cuadernos del Seminario I. Los límites de la literatura, editado por Alberto Giordano. Centro de Estudios de Literatura Argentina, 2010.

Foucault, Michel. “¿Qué es la ilustración?”. Saber y Verdad. Las Ediciones de la Piqueta, 1991.

Gramuglio, María Teresa. “El lugar de Saer”. Juan José Saer por Juan José Saer. Editorial Celtia, 1986. pp. 261-299.

Gramuglio, María Teresa. "Increíbles aventuras de una nieta de la cautiva". Punto de Vista, n. ${ }^{0} 14$, marzo-julio de 1982, pp. 27-28.

Gramuglio, María Teresa, et al. "Literatura, mercado y crítica. Un debate”. Punto de Vista, n. 66, abril del 2000, pp. 1-9.

Ludmer, Josefina. "Literaturas postautónomas". Diciembre de 2006, http://www.lehman.cuny.edu/ciberletras/v17/1 udmer.htm.

Ludmer, Josefina. “Literaturas postautónomas 2". Mayo de 2007.

Marimón, Antonio. "Un best-seller argentino: las mil caras de un pícaro (reseña bibliográfica: Flores robadas en los jardines de Quilmes de Jorge Asís)". Punto de Vista, n. ${ }^{\circ}$ 14, marzo-julio de 1982, pp. 24-27.

Podlubne, Judith. "Beatriz Sarlo / Horacio González: perspectivas de la crítica cultural". Las operaciones de la crítica, compilado por Alberto Giordano y María Celia Vázquez. Beatriz Viterbo, 1998.

Porrúa, Ana. "César Aira, imposición y juventud”. Punto de Vista, n. ${ }^{\circ} 81$, abril del 2005, pp. $24-29$.

Sarlo, Beatriz. “3 novelas argentinas-Saer, Tizón, Conti”. Los Libros, n. 44 , enero-febrero de 1976, p. 3.

Sarlo, Beatriz. "Afinidades electivas". Ficciones argentinas: 33 ensayos. Mardulce, 2012, pp. 27-31.

Sarlo, Beatriz. "Amor de ciudad”. Ficciones argentinas: 33 ensayos. Mardulce, 2012, pp. 45-49.

Sarlo, Beatriz. "Anomalías". Punto de Vista, n. ${ }^{\circ}$ 57, abril de 1997, pp. $21-23$.

Sarlo, Beatriz. "Anomalías. Sobre la narrativa de Sergio Chejfee". Escritos sobre literatura argentina. Siglo XXI, 2007, pp. 394-397.

Sarlo, Beatriz. "Barthesianos de por vida". Plan de operaciones. Sobre Borges, Benjamin, Barthes y Sontag. Ediciones Universidad Diego Portales, 2013, p. 11.

Sarlo, Beatriz. "Cold porno". Ficciones argentinas: 33 ensayos. Mardulce, 2012, pp. 135-139.

Sarlo, Beatriz. "El imitador de voces”. Ficciones argentinas: 33 ensayos. Mardulce, 2012, pp. 171-175.

Sarlo, Beatriz. "El rolex de Aira". Ficciones argentinas: 33 ensayos. Mardulce, 2012, pp. 39-43.

Sarlo, Beatriz. "El tiempo inagotable". Escritos sobre literatura argentina. Siglo XXI, 2007, pp. 317-320.

Sarlo, Beatriz. "El tiempo inagotable”. La Nación, 2005, https://www.lanacion.com.ar/cultura/juan-jose-saer-y-la-gr ande-nid743591\%.

Sarlo, Beatriz. Escenas de la vida posmoderna. Ariel, 1994.

Sarlo, Beatriz. Escritos sobre literatura argentina. Siglo XXI, 2007.

Sarlo, Beatriz. "Experiencia y lenguaje". Escritos sobre literatura argentina. Siglo XXI, 2007, pp. 401-403.

Sarlo, Beatriz. Ficciones argentinas. 33 ensayos. Mardulce, 2012.

Sarlo, Beatriz. "Ficciones del saber". Escritos sobre literatura argentina. Siglo XXI, 2007, pp. 356-357.

Sarlo, Beatriz. "Fin del mundo". Ficciones argentinas: 33 ensayos. Mardulce, 2012, pp. 201-205.

Sarlo, Beatriz. "Fogwill, la experiencia sensible". Punto de Vista, n. ${ }^{\circ}$ 71, diciembre de 2001, pp. 27-31.

Sarlo, Beatriz. "Género nostálgico". Escritos sobre literatura argentina. Siglo XXI, 2007, pp. 364-365.

Sarlo, Beatriz. “Gore explícito”. Ficciones argentinas: 33 ensayos. Mardulce, 2012, pp. 117-121. 
Sarlo, Beatriz. "La condición mortal". Escritos sobre literatura argentina. Siglo XXI, 2007, pp. 289-295.

Sarlo, Beatriz. "La condición mortal". Punto de Vista, n. 46 , agosto de 1993, pp. 28-30.

Sarlo, Beatriz. "La extensión”. Escritos sobre literatura argentina. Siglo XXI, 2007, pp. 444-445.

Sarlo, Beatriz. "La ficción inteligente (sobre El aire)". Suplemento "Cultura y Nación". Clarín, 12 de noviembre de 1992, p. AU1.

Sarlo, Beatriz. "La inteligencia”. Ficciones argentinas: 33 ensayos. Mardulce, 2012, pp. 177-181.

Sarlo, Beatriz. "La novela como viaje". Escritos sobre literatura argentina. Siglo XXI, 2007, pp. 358-360.

Sarlo, Beatriz. "La novela después de la historia. Sujetos y tecnologías". Escritos sobre literatura argentina. Siglo XXI, 2007, pp. 471-482.

Sarlo, Beatriz. "La originalidad y el recato". Ficciones argentinas: 33 ensayos. Mardulce, 2012, pp. 69-73.

Sarlo, Beatriz. "La última flor azul". Ficciones argentinas: 33 ensayos. Mardulce, 2012, pp. 123-127.

Sarlo, Beatriz. "Leer sin referencias". Ficciones argentinas: 33 ensayos. Mardulce, 2012, pp. 99-103.

Sarlo, Beatriz. "Lugar de origen”. Escritos sobre literatura argentina. Siglo XXI, 2007, pp. 404-411.

Sarlo, Beatriz. "Luminosa oscuridad". Ficciones argentinas: 33 ensayos. Mardulce, 2012, pp. 183-187.

Sarlo, Beatriz. "Melancolía e insistencia de la novela". Punto de Vista, n. ${ }^{\circ}$ 90, abril de 2008, pp. 13-17.

Sarlo, Beatriz. "Monstruos cotidianos". Ficciones argentinas: 33 ensayos. Mardulce, 2012, pp. 141-145.

Sarlo, Beatriz. "Narrar la percepción”. Escritos sobre literatura argentina. Siglo XXI, 2007, pp. 281-285.

Sarlo, Beatriz. "Narrar la percepción”. Punto de Vista, n. ${ }^{\circ}$ 10, noviembre de 1980, pp. 34-27.

Sarlo, Beatriz. "Objeto sólido e inestable". Ficciones argentinas: 33 ensayos. Mardulce, 2012, pp. 147-151.

Sarlo, Beatriz. "Oralidad y lenguas extranjeras. El conflicto en la literatura argentina durante el primer tercio del siglo XX”. Ensayos argentinos. De Sarmiento a la vanguardia, por Carlos Altamirano y Beatriz Sarlo, Ariel, 1997, pp. 269-288.

Sarlo, Beatriz. "Paisaje y signos". Ficciones argentinas: 33 ensayos. Mardulce, 2012, pp. 81-85.

Sarlo, Beatriz. "Phoenix, lejos del centro". Ficciones argentinas: 33 ensayos. Mardulce, 2012, pp. 93-97.

Sarlo, Beatriz. Plan de operaciones. Sobre Borges, Benjamin, Barthes y Sontag. Ediciones Universidad Diego Portales, 2013.

Sarlo, Beatriz. "Poderes benevolentes". Escritos sobre literatura argentina. Siglo XXI, 2007, pp. 384-386.

Sarlo, Beatriz. "Política, ideología y figuración literaria". Escritos sobre literatura argentina. Siglo XXI, 2007, pp. 337-355.

Sarlo, Beatriz. “¿Pornografía o fashion?”. Escritos sobre literatura argentina. Siglo XXI, 2007, pp. 462-470.

Sarlo, Beatriz. “¿Pornografía o fashion?”. Punto de Vista, n. ${ }^{\circ}$ 83, diciembre de 2005, pp. 13-17.

Sarlo, Beatriz. Prólogo. La preparación de la novela: notas de cursos y seminarios en el Collège de France, 1978-1979 y 1979-1980, por Roland Barthes, traducido por Patricia Willson, Siglo XXI, 2005, pp. 15-24.

Sarlo, Beatriz. "Roland Barthes: una biografía imposible". Plan de operaciones. Sobre Borges, Benjamin, Barthesy Sontag. Ediciones Universidad Diego Portales, 2013, pp. 26-30.

Sarlo, Beatriz. "Sueño de la razón argentina”. Escritos sobre literatura argentina. Siglo XXI, 2007, pp. 454-461.

Sarlo, Beatriz. "Sujetos y tecnologías. La novela después de la historia". Punto de Vista, n. ${ }^{\circ} 86$, diciembre de 2006, pp. 7-11.

Sarlo, Beatriz. "Un relato inconsumible". Escritos sobre literatura argentina. Siglo XXI, 2007, pp. 441-443.

Sarlo, Beatriz. "Una cultura, varias ciudades, dos novelas". Escritos sobre literatura argentina. Siglo XXI, 2007, pp. 431-440.

Sarlo, Beatriz. "Una poética de la incertidumbre”. Escritos sobre literatura argentina. Siglo XXI, 2007, pp. 306-309.

Sarlo, Beatriz. "Vivir para leer, leer para escribir". Ficciones argentinas: 33 ensayos. Mardulce, 2012, pp. 87-91.

Sarlo, Beatriz. Zona Saer. Ediciones Universidad Diego Portales, 2016. 


\section{Notas}

* Artículo de investigación. El artículo se enmarca en el proyecto de investigación "Estados de la ficción en textualidades latinoamericanas contemporáneas: Teoría y Crítica”, desarrollado para Conicet, en el período 2016-2017.

[1] Enfrentada con "los límites del sufrimiento exasperado y la muerte", y con "una realidad cuyos sentidos permanecían ocultos", en los años ochenta — argumenta Sarlo—, la literatura argentina "buscó modalidades más oblicuas para colocarse en una relación significativa respecto del presente y comenzar a construir un sentido de la masa caótica de experiencias escindidas de sus explicaciones colectivas" ("Política" 349-350). La hipótesis está en el ensayo "Política, ideología y figuración literaria” (1987), incluido en Escritos sobre literatura argentina .

[2] La hipótesis (adorniana) sobre el contenido de verdad de la obra de arte puede encontrase en el mismo ensayo, por ejemplo, en esta cita: "Estos relatos, o los mejores de ellos, en momentos donde muchas otras formas de discurso callaban, hablaron de aquello que la voz del poder ocultaba o naturalizaba; despojaron de contenido moral a su discurso sobre la muerte y exhibieron las fisuras por donde puede verse, para decirlo con palabras de Adorno, 'aquello que la ideología ocultaba, es decir, también, lo que es posible padecer, pero difícil convertir en discurso"” ("Política” 345).

[3] El artículo "Política, ideología y figuración literaria" fue originalmente publicado en Balderston, Daniel, et al. Ficción y politica. La narrativa argentina durante proceso militar. Alianza Estudio, 1987; “¿Pornografía o fashion?”, en Punto de Vista, n. 83 (diciembre 2005); y “Sujetos y tecnologías. La novela después de la historia”, en Punto de Vista, n. 86 (diciembre 2006).

[4] Dice Sarlo que la narrativa escrita y publicada entre 1975 y 1986 presenta la disimetría entre el orden de lo real y el orden del discurso como una cuestión estética fundamental, "incluso en aquellos textos que parecen más inclinados a afirmar la posibilidad de la representación" ("Política” 330). La nota a pie que abre aquí remite, como ejemplo, a las variaciones que se dan entre narrador y autor en Flores robadas en los jardines de Quilmes. Para la distancia que Punto de Vista marcó en relación con la literatura de Jorge Asís, puede leerse el artículo de Antonio Marimón.

[5] Originalmente publicado como "Fogwill, la experiencia sensible" en Punto de Vista, n. 71 (diciembre de 2001).

[6] En la primera etapa de la revista, y durante los primeros años de César Aira en escena, Punto de Vista publicó "Increíbles aventuras de una nieta de la cautiva” (sobre Ema, la cautiva), de María Teresa Gramuglio y "Los gestos de la posmodernidad” (sobre Canto Castrato), de Nora Catelli. Dieciséis años después, Matilde Sánchez trae el nombre de Aira a "la mesa de discusión”, cuando propone pensarlo en relación con los nombres de Piglia y Saer que, junto con el de Puig, Sarlo sugería que podían ser las nuevas marcas en la literatura argentina, después de las de Borges y Cortázar; el debate puede leerse en Gramuglio et al. Unos meses antes de “¿Pornografía o fashion?” se publica "César Aira: implosión y juventud” de Ana Porrúa.

[7] Desarrollé las implicancias de la atribución de estas cualidades a la literatura de Aira en "En torno a las lecturas del presente" (Contreras 141-143).

[8] Por ejemplo: la reticencia al abismo de la representación costumbrista de Fuego a discreción de Antonio Dal Masetto ("La novela como viaje” 359); la confianza de Andrés Rivera en el contenido de verdad del arte que le hace prescindir, por ejemplo, en Apuestas, de los típicos artificios de explicación realistas ("La novela después” 368); el cosmopolitismo viajero de Matilde Sánchez, quien en La canción de las ciudades sabe sortear todas las trampas del exotismo y del pintoresquismo ("Una cultura” 437).

[9] Puede confrontarse la extensión y profundidad de estos argumentos con, por ejemplo, los más rápidos que se esgrimen para sentar reparos ante la superficialidad de una novela, como Probibido escupir sangre de Guillermo Saccomano ("Género nostálgico" 364-365).

[10] Subrayo aquí la cita de Sarlo que Podlubne toma de la página 189 de Escenas de la vida posmoderna: "La escucha y el diálogo viven de una distancia media: ni la proximidad de las comunidades cerradas que solo pueden tolerar sus propios discursos [...] ni la distancia, a veces llamada utópica, que coloca en un mundo futuro completamente transformado el único escenario respecto del cual es posible medir los problemas presentes. Ni neotribus ni mundos imaginarios”.

[11] No casualmente el objeto de análisis en las novelas de Cucurto, Paula y Link es la lengua y la forma en que los personajes hablan y entablan sus diálogos. En este sentido podría pensarse que es precisamente cuando experimenta algo parecido a un "quedar fuera de la conversación" (de ahí sus subrayados: "lo in de lo in", lo "cool”) que predomina en el ensayo la inclinación a prevenirse contra la posibilidad de ser identificada como "los que leen mal" y a responder anticipadamente a esa acusación. Por ejemplo: "Por supuesto, hay tedio en la repetición, pero como las palabras que se repiten son tan extrañas a la literatura, nadie lo señala porque 
la sorpresa del exotismo social se combina con el peligro de la incorrección ideológica que amenaza a quienes lean 'mal' las voces de Cucurto" ("La novela después" 479).

[12] Véase "Poderes benevolentes", publicado por primera vez en Escritos sobre literatura argentina y fechado en 1989.

[13] Remito al artículo "Oralidad y lenguas extranjeras. El conflicto en la literatura argentina durante el primer tercio del siglo XX".

[14] Cuando lee La canción de las ciudades, Sarlo deja enunciada la sospecha de que los hechos contados le sucedieron también a la narradora de (que es) Matilde Sánchez. Y dice: "Nunca puede saberse, como tampoco puede evitarse la voluntad de saber" ("Una cultura" 438).

[15] Véase "La ficción inteligente (sobre El aire)" y “Anomalías", originalmente publicado en Punto de Vista, n. 57 (abril de 1997). Entre paréntesis, que Sarlo polemice con lo que se lee como "lo nuevo" de ningún modo debería hacernos olvidar que su ejercicio crítico siempre buscó, en el sentido de la ontología del presente de Foucault, someterse a la prueba de la realidad y de la actualidad según una actitud experimental, y que leer en presente siempre consistió también, y quizás, ante todo, en el desafío y el placer de una confrontación periódica con la novedad.

[16] Un signo extra de su lugar excesivo en la crítica de Sarlo podría estar dado por el hecho de que, de los cuatro escritores "etnográficos" del presente, Cucurto es el único que vuelve en Ficciones argentinas, cuando reaparece el problema de la imitación literaria de las lenguas del presente. Me referiré a esto más adelante.

[17] Hay, con todo, un último mapa. Es el que diagrama en el ensayo que publica en el último número de Punto de Vista 90 (abril del 2008) y que titula, significativamente, "Melancolía e insistencia de la novela". Nuevamente, como en los mapas de 2005 y 2006 , el deslinde es claro: de un lado, Berazachussetts, de Leandro Ávalos Blacha, emblema de las novelas que malentienden el legado de César Aira y llevan al extremo del inverosímil más superficial y hasta infantil una "fantasía desbocada que no explica su lógica" (15), porque no la tiene; del otro, Peripecias del no de Luis Chitarroni, "después de la muerte de Libertella” probablemente el libro más "desesperado e insensato" y al mismo tiempo más "literario y erudito" (14), y El trabajo de Aníbal Jarkowsky, una novela en la que "lo informe y proliferante del imaginario coagula en historias que nunca son arbitrarias ni responden al capricho" (17). Como se ve, y nuevamente, el valor ya no está puesto en la distancia crítica en la mímesis, sino en la verosimilitud compositiva, en el arte y el rigor con que el relato articula sentido y experimentación. Pero más interesante que eso es el modo en el que Sarlo, que para ese entonces ya prologó la traducción al español de La preparación de la novela, elige describir el lugar diverso que la literatura tiene en el sistema argentino contemporáneo (una vez que la interpretación del pasado está a cargo de otros discursos, "el lugar de la literatura ha pasado a ser otro", decía en 2006) con la lengua del último Barthes, en términos, por cierto, más amplios y con resonancias más contemporáneas que argentinas, de no-lugar. La inscripción de una utopía literaria en el sentido fuerte (como la "inscripción de un deseo de novela que no tiene lugar en la literatura contemporánea" [La preparación 16]) que Sarlo lee en su prólogo como la apuesta teórica y práctica (vital) de Barthes en la escritura, se traduce en la elección de dos novelas fundadas en un mismo impulso melancólico que, bajo la forma del "ya no, pero sin embargo", reconoce habitar las ruinas de la literatura, mientras insiste en el orden sostenido de la ficción; dos novelas cuyos títulos, por lo demás, se vuelven, por efecto de la transformación del mapa, cifras emblemáticas del no-lugar de la literatura en la contemporaneidad: la negatividad lleva al extremo y a la exhaustividad, y a la perfección del trabajo formal.

[18] Véase "Monstruos cotidianos".

[19] Para el caso de Mariana Enríquez, véase “Gore explicito”; para el caso de Matilde Sánchez, véase “ Cold porno”.

[20] Véase "La inteligencia”.

[21] Véase "La originalidad y el recato".

[22] El estilo es, por ejemplo, el siguiente: "No podría callar que 'Frío en Alaska' me llevó a releer un cuento extraordinario, escrito en 1970, por Elvio Gandolfo: Vivir en la salina" (sobre Frío en Alaska, de Matías Capelli ["Paisaje y signos" 85]); "Misteriosa y tersa, la narración termina con palabras cuya resonancia llega desde Borges: 'un cuchillito de hueso'. No están para evocarlo. Se lo evocan a esta lectora" (sobre Unas polillas, de Pedro Lipcovich ["La última flor azul" 127]); "Viene al recuerdo Italo Svevo, e inmediatamente lo descarto. Esta novela no es melancólica. Viene a la memoria Beckett, y parece más adecuado" (sobre Cuentas pendientes, de Martín Kohan ["Lo blando y lo podrido" 129]). Los ensayos sobre Coelho y Ronsino son, respectivamente, "Amor de ciudad” (sobre Ida) y "Afinidades electivas” (sobre La descomposición).

[23] El artículo más antiguo de la recopilación de Escritos sobre literatura argentina es "Narrar la percepción" (sobre Nadie nada nunca), originalmente publicado en Punto de Vista, n. ${ }^{\circ} 10$ (noviembre de 1980). El último, "El tiempo inagotable" (sobre La 
grande) fue originalmente publicado en "Cultura", suplemento de La Nación (2 de octubre de 2005). Como dice en el prólogo, Sarlo solo incluye en el volumen los artículos publicados después de esa fecha, que son los que —entiende- pueden seguir siendo leídos hoy (descarta entonces el artículo “3 novelas argentinas. Saer, Tizón, Conti”, que incluía un análisis sobre El limonero real y había publicado en Los libros , n. ${ }^{\circ} 44$ (enero-febrero de 1976).

[24] Los ensayos a los que me remití recién son: "Narrar la percepción" (1980); "Política, ideología y figuración literaria" (1987); "La condición mortal" (originalmente publicado en Punto de Vista, n. ${ }^{\circ}$ 46, agosto de 1993); todos ellos incluidos en Escritos sobre literatura argentina. Y el reciente libro de 2016, Zona Saer.

\section{Licencia Creative Commons CC BY 4.0}

Cómo citar este artículo: Contreras, Sandra. "Beatriz Sarlo, las lenguas del presente". Cuadernos de Literatura, vol. 24, 2020. https://doi.org/10.11144/Javeriana.cl24.bslp 